\title{
Price cap regulation and water quality
}

\section{Thomas Bue Bjørner $^{1}$ • Jacob Victor Hansen ${ }^{1}$. Astrid Fanger Jakobsen ${ }^{1}$}

Accepted: 5 September 2021 / Published online: 22 October 2021

(c) The Author(s) 2021

\begin{abstract}
A number of studies suggest that price cap regulation may reduce the quality of the regulated good. This paper analyzes the impact on drinking water quality of a shift from cost-of-service to price cap regulation in Denmark, using a balanced panel of drinking water companies, for the period 2008 to 2016. The price cap was introduced in 2011 for companies above a certain threshold size. We exploit this quasi-experimental setting to estimate the impact of the shift in regulation using a regression discontinuity difference-in-differences approach. Our measure of drinking water quality is based on results from a compulsory surveillance drinking water testing program, which investigates whether or not water samples contain a level of microbiological content that exceeds limit values. More specifically, we compare the change over time in water quality for a treatment group of 113 companies regulated with price caps that have a size close to the threshold size for being regulated, with the change in drinking water quality for a control group of 282 companies that are below but close to the threshold size. We find that the shift in regulation has not caused a reduction in drinking water quality in Denmark.
\end{abstract}

Keywords Price cap · Drinking water quality · Quasi-experiment · Regression discontinuity $\cdot$ Multi-period difference-in-differences

JEL classification C21 $\cdot$ L15 $\cdot$ L51 $\cdot$ L95 $\cdot$ Q25

\footnotetext{
The opinions expressed and arguments employed are those of the authors and do not necessarily reflect the official views of the Danish Competition and Consumer Authority. We have benefitted from input and suggestions from directors and colleagues at the Danish Competition and Consumer Authority, Bolette Dorrit Jensen at the Danish Environmental Protection Agency, and from Jesper Gerhardt Christiansen. We are also very grateful for comments from two anonymous referees. The usual disclaimers apply.

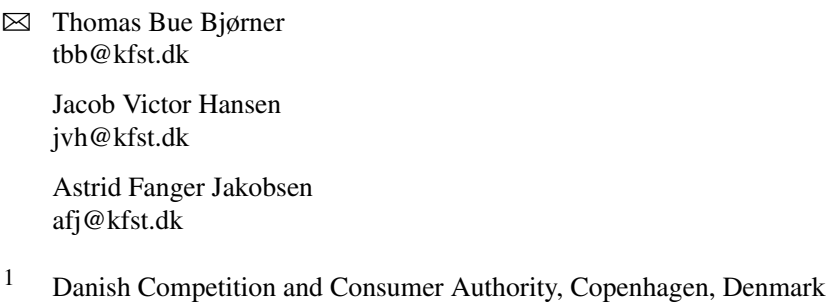




\section{Introduction}

Secure supply of safe drinking water is crucial for welfare and is one of the United Nations global development goals. Typically, local monopolies supply drinking water. As in other utility sectors, drinking water companies are often subject to various forms of economic regulation to prevent the companies from exploiting their monopoly power.

In Denmark, regulation of larger drinking water companies changed from costof-service regulation to price cap regulation in 2011. This change in regulation was motivated by studies showing that production in the Danish drinking water sector was inefficient, with costs being too high; see the Danish Competition Authority (2003) and the Danish Economic Councils (2004). In general, high costs in cost-of-service regulated natural monopolies reflect the lack of incentives encouraging managerial effort and reduction of $\mathrm{x}$-inefficiency associated with cost-of-service regulation; see Joskow (2007).

The change in the regulatory regime in Denmark was aimed at reducing the cost and ultimately the price of drinking water. To accomplish this, the price caps were gradually reduced over time requiring the regulated drinking water companies to reduce their costs. However, there have been some concerns in Denmark that the gain from lower costs due to the price cap comes at the expense of deteriorating drinking water quality and security of supply. The purpose of this article is to estimate the effect on drinking water quality of the change in regulatory regime for larger drinking water companies in Denmark from cost-of-service to price cap regulation.

In principle, a price cap put on a profit maximizing monopoly supplier of a single product can be expected to reduce the quality of the product compared to a situation without any regulation; see Sappington (2005). ${ }^{1}$ A number of empirical studies have investigated the effect on product quality of introducing incentive regulation like price caps in the telecommunication and the electricity distribution sectors. The empirical studies on the effect of incentive regulation for telecommunication companies have found that some measures of service quality have improved under incentive regulation, while others have regressed; see Ai et al. (2004), Ai and Sappington (2005), Banerjee (2003), Clements (2004) and Roycroft and Garcia-Murrilo (2000). ${ }^{2}$

For the electricity distribution sector, studies suggest that security of supply-measured by power outage duration (minutes) or frequency of outage episodes - has deteriorated under price cap regulation as compared to cost-of-service type regulation; see Schmidthaler et al. (2015), Ter-Martirosyan and Kwoka (2010) and Reichl

\footnotetext{
1 Note that this does not necessarily apply if the profit maximizing monopoly supplier provides different variants of the good with different levels of quality. In that case, a price cap can make it profitable for the monopoly to increase the quality of the low quality variants; see Sappington (2005). In addition, note that a reduction in the quality of a monopoly supplier of a single product is expected theoretically, when regulation for a profit maximizing monopoly change from no regulation to price cap regulation. As pointed out by one of the anonymous referees, this does not tell us whether quality goes up or down when moving from cost-of-service regulation (for companies not maximizing profit) to price caps.

2 Sappington and Weisman (2010) offer some potential explanations for why some measure of quality improved in the telecommunication companies. Note also that the studies of the effects of regulating telecommunication companies took place when the provision of telecommunication services relied on physical, wired connections, i.e. when telecommunication companies were natural monopolies.
} 
et al. (2008). The first two of these studies also investigated the effect of combining low cost incentive regulation with so-called "output-based" regulation. Output-based regulation is regulation that, in addition to the low cost incentive regulation, provides incentives for high quality. Both studies found that output-based regulation increased security of the electricity supply compared to incentive regulation like price caps that only focus on low cost.

The above studies all measure the effect of regulation by regressing a variable that measures quality on a measure of the regulatory regime and add some control variables to this estimation. One of the methodological challenges of these studies is that the choice of regulatory regime is likely to depend on the level of security of supply. Thus, the measure of the regulatory regime may be an endogenous variable. In principle, the problem of endogenous explanatory variables can be solved by applying instrumental variables techniques. This approach is also adopted in several of the above-mentioned empirical studies of the effect of incentive regulation on quality or security of supply. However, the validity of instrumental variables techniques relies on strong assumptions. ${ }^{3}$ If these assumptions are not satisfied, it can cause bias; see Angrist and Krueger (2001) and Bound et al. (1995). In practice, it is often hard to find instruments that satisfy the assumptions.

In this study, we examine the effect of price cap regulation on a measure of drinking water quality for Danish drinking water companies using a quasi-experimental design. The study uses company-level data for the period 2008 to 2016. The price cap regulation was introduced for water companies above a certain threshold size in 2011. Thus, the applied data contain information about water quality for all companies before the price cap regulation was introduced, and information about water quality for the drinking water companies with and without price cap regulation (depending on the size of the company) after the price cap regulation was implemented.

These data allow us to carry out a quasi-experimental analysis of the effect of price cap regulation on water quality. We do this by estimating simple and multiperiod difference-in-differences models using a regression discontinuity approach. More specifically, we compare the change over time in water quality for a "treatment" group of companies, which became regulated with price caps in 2011, with the change over time in water quality for a "control" group of companies, which did not become price cap regulated in 2011. The treatment group consists of 113 companies above the threshold size for being regulated, while the control group consists of 282 companies below the threshold size. There are large differences in the size of drinking water companies in Denmark. The smallest drinking water companies may provide drinking water to only a dozen of rural households, while the largest companies provide drinking water to urban consumers in the largest Danish cities. To make our treatment and control groups of companies reasonably comparable, we do not include very large companies in the treatment group and we do not include (very) small companies in the control group.

\footnotetext{
3 The instrumental variable(s) should not correlate with the explained variable in any other way than through the explanatory variable, and the instrumental variable(s) should (strongly) correlate with the explanatory variable of interest (in this case the regulatory regime).
} 
Our study contributes to the literature on monopoly regulation and service quality in different ways. First, we are not aware of any other studies that have adopted a quasiexperimental approach to estimate the effect of price cap regulation on the quality or security of supply of the regulated good. Secondly, previous studies appear to have looked only at the effect of economic incentive regulation on electricity distribution and telecommunication services. Thus, we have not identified any previous studies looking at the effect of regulation on water quality. Finally, we have data at company level for a very large number of companies compared to previous studies.

We find that water quality has improved both for companies that shifted from costof-service regulation to price caps in 2011 (the treatment group) and for companies that had cost-of-service regulation in the whole period covered by the data (the control group). In addition, the improvement is fairly similar for our treatment and control group. Thus, water quality does not appear to have deteriorated due to the implementation of the price cap regulation. In fact, results from some of the estimated models suggest that price cap regulation has improved water quality. The overall conclusion is supported by sensitivity analyses and supporting evidence looking at other measures of the quality and security of supply of the regulated water companies.

In the following section, we describe the regulation of drinking water companies in Denmark. In Sect. 3, we outline the quasi-experimental design and the regression models, while in Sect. 4 we present the applied data. Estimation results follow in Sect. 5, and in Sect. 6, we present some supporting evidence. Finally, Sect. 7 contains the conclusion and a discussion of the results.

\section{Regulation of drinking water companies in Denmark}

Drinking water in Denmark is obtained from groundwater. In most parts of the country, the groundwater can be used as drinking water after only simple treatment, such as water aeration and filtration.

The Danish drinking water sector consists of more than 2,000 small and mediumsized drinking water companies, but there also exist some larger companies in the biggest Danish cities. The companies provide drinking water to most of the 3 million Danish households and other customers in the private and public sector. The drinking water companies are owned by local public authorities (municipalities) or are customer owned.

Before 2011, all water companies were regulated only with cost-of-service regulation, where the companies were not allowed to generate higher revenue than their expenditure. In addition, the drinking water companies were (and are still today) not allowed to generate and return profits to their owners. As in many other countries, this regulation was associated with a lack of efficiency and low productivity over time.

In June 2009, new legislation was passed which introduced price cap regulation with effect from 2011 for all larger water companies. The threshold for being regulated with a price cap is defined by the annual amount of water sold. Companies who sold more than $200,000 \mathrm{~m}^{3}$ of water annually received a price cap.

In real terms, the price cap was reduced over time, subject to a measure of the expected productivity gain in the drinking water sector, following the RPI-X principle. 
Table 1 Overview of regulation of Danish drinking water companies

\begin{tabular}{lll}
\hline $\begin{array}{l}\text { Company size (annual amount of } \\
\text { water sold) }\end{array}$ & Before 2011 & From 2011 ${ }^{\text {a) }}$ \\
\hline $\begin{array}{l}\text { Less than } 200,000 \mathrm{~m}^{3} \\
\text { Above } 200,000 \mathrm{~m}^{3}\end{array}$ & $\begin{array}{l}\text { Cost-of-service } \\
\text { Cost-of-service }\end{array}$ & $\begin{array}{l}\text { Cost-of-service } \\
\text { Price cap with RPI-X reduction plus } \\
\text { yardstick reduction depending on } \\
\text { benchmarking }\end{array}$ \\
\hline
\end{tabular}
a) In 2016, a revenue cap replaced the price cap. In addition, the yardstick element in the regulation was
cancelled for medium-sized drinking water companies $\left(200,000\right.$ to $800,000 \mathrm{~m}^{3}$ sold water)

The regulated drinking water companies were also benchmarked annually using a DEA benchmarking model. Companies that, according to the benchmarking, had excessive costs of production received an additional "individual" reduction in their price cap. That is, a supplementary element of yardstick cost regulation. Table 1 summarizes the regulation introduced in $2011 .^{4}$

Smaller drinking water companies selling less than $200,000 \mathrm{~m}^{3}$ annually were not included in the new price cap and benchmarking regulation. According to the explanatory notes to the law implemented in 2011, the motivation for this was that it was believed that the administrative burden of providing information for benchmarking to the regulator would be disproportionately large compared to the potential efficiency gain of having price cap regulation:

\section{"This threshold (the 200,000 $\mathrm{m}^{3}$ threshold, ed.) is set to make sure that the around 2,400 smaller water companies is not imposed unreasonable administrative bur- dens for benchmarking [...] Since these smaller water companies only deliver around 20 percent of the total extracted volume of water, the potential for effi- ciency improvements is limited." (own translation). ${ }^{5}$}

In the explanatory notes to the law, there is no motivation for the exact choice of threshold size. The exact choice of the threshold size appears to have been determined in an ad hoc way in order to ensure that most of the market (sales volumes) would be covered by the new regulation without pressing new regulation down on a large number of rather small companies covering a limited share of the total market. ${ }^{6}$

\footnotetext{
4 The description of the regulation does not include recent modifications made since the period covered by the analyzed data.

5 Explanatory notes to the Danish law about the water sector ("Vandsektorloven"), 26 February, 2009. See the following website: https://www.retsinformation.dk/eli/ft/200812L00150 in the following section: "Bemærkninger til lovforslagets enkelte bestemmelser", and the following subsection: "Til § 2".

6 It is important to note, that there is no indication in the explanatory notes that the small drinking water companies in our control group were exempted from the new regulation, because they were believed to operate efficiently (as opposed to the drinking water companies above the threshold size). If that had been the case, it would be problematic to apply the regression discontinuity approach for identifying the effect of the regulation (see Sect. 3).
} 
The accumulated reduction in the price caps from 2011 to 2016 was more than DKK 400 million, or around 14 percent of the price cap-regulated companies' production costs in 2016. The reduction in the price caps was extraordinarily large in 2012 (DKK 240 million), ${ }^{7}$ but in subsequent years the annual cost reduction requirement corresponded 1 to 2 percent of the annual production costs for the price cap-regulated companies.

Note that the Danish companies regulated with the price cap are still not allowed to generate and return profits to their owners. For profit maximizing companies, a price cap yields an incentive to reduce costs, because cost reductions increase profits. This incentive is not present in this case, but the price cap-regulated companies are still required to lower their costs. It is the effect on quality of this cost reduction requirement, which we aim to identify in this study.

\section{Quasi-experimental design and the econometric framework}

The change in the regulatory regime described in Sect. 2 provides us with the opportunity to estimate the effect of the changed regulation. Ideally, to estimate the effect of a change in economic regulation, we should let a randomly chosen sample of the Danish water companies undergo price cap regulation and leave the rest of the companies with the cost-of-service regulation. We would then be able to estimate the effect of regulation by comparing water quality over time for companies under the new type of regulation with the change in water quality over time for the companies with unchanged regulation. This would leave us with exogenous variation, since all companies (across company characteristics) would have the same likelihood of experiencing a change in regulation. However, such natural experiments are very rare in practice.

Instead, we use a quasi-experimental approach to estimate the effect of a change in economic regulation on water quality. This approach imitates the natural experiment explained above. More precisely, we exploit the fact that regulation of Danish water companies above a certain threshold size $\left(200,000 \mathrm{~m}^{3}\right.$ of water sold per year) changed in 2011, while the regulation of companies of a size below this threshold was left unchanged.

Thistlethwaite and Campbell (1960) first introduced the concept of estimating causal effects by comparing units below and above a threshold determining if the unit were exposed or were not exposed to treatment. The main idea of this approach is to compare the value of some outcome variable for units not too far above the threshold with the value for units not too far below the threshold. This is known as the regression discontinuity design. ${ }^{8}$

\footnotetext{
7 This was due to an extraordinary downward correction of the price cap for some companies that, prior to the correction, had their price cap calculated based on costs that exceeded their actual costs.

8 Our applied quasi-experimental design closely relates to a regression discontinuity design, i.e. we use the same methodological considerations. However, rather than formally applying a regression discontinuity design in the traditional sense, such as the infamous one in Black (1999), we estimate difference-indifferences models comparing pre-trends for a treatment group and a control group.
} 
The advantage of comparing companies of almost equal size is that they are likely to have comparable (unobserved) company characteristics. Thus, we would also expect that these companies would react identically to a change in regulation; see Lee and Lemieux (2010), Angrist and Pischke (2009) and Cook (2008) for discussions of the regression discontinuity design. The approach is regularly applied in a number of different research areas; see Hilton Boon et al. (2021) and Li et al. (2020).

For the threshold to be relevant to use in a quasi-experimental setting, it is important that the companies below and above the threshold are similar in the sense that they can be expected to react identically to the change in regulation. If a certain threshold for being regulated is chosen because the policy maker knows that companies above and below the threshold have different characteristics, or would react differently to the change in regulation, it is not relevant to apply a regression discontinuity design. However, as noted in the previous section there is nothing in the explanatory notes to the law implemented in 2011 that indicates that the $200,000 \mathrm{~m}^{3}$-threshold was chosen based on knowledge that companies slightly below the limit were systematically different from the companies slightly above the threshold.

Ideally we want to compare water quality over time for a control group of companies with a volume of extracted water slightly below the $200,000 \mathrm{~m}^{3}$-threshold, with water quality for a treatment group of companies with a volume of extracted water slightly above this threshold that were subject to the change in regulation. However, if we only included companies with a size only slightly above and slightly below the threshold, there would be very few companies in the control and treatment group, respectively. Therefore, in practice we need to expand the bandwidth that we use to define which companies to include in the analysis. We focus on companies who extract at least 100,000 and at most $500,000 \mathrm{~m}^{3}$ of water; see Sect. 4 .

As far as we are aware, no previous studies have used a quasi-experimental approach to analyze how a change in regulation of utility monopolies has affected quality. In addition, we have not found any studies looking at the effect of regulation on quality for drinking water companies.

\subsection{Econometric framework}

We set up two econometric models to study the effect of a change in regulation. The first model is a basic difference-in-differences model; see Wooldridge (2015). We estimate the following equation:

$$
y_{i t}=\alpha+\tau_{i}+\beta \cdot D_{i}+\gamma \cdot I\left[t \geq t_{T}\right]+\delta \cdot D_{i} \cdot I\left[t \geq t_{T}\right]+\epsilon_{i t},
$$

where $y_{i t}$ denotes company $i$ 's inverse measure of water quality in year $t, \alpha$ is a constant measuring the average water quality for the control group before the treatment year, $t_{T}$ (2011), $\tau_{i}$ is a company-level fixed effect, $D_{i}$ is a treatment group dummy, $I\left[t \geq t_{T}\right]$ indicates whether the year is before or after the treatment year, and $\epsilon_{i t}$ is an error term capturing all unexplained variation in $y_{i t} . \beta$ is a parameter capturing the level effect for the treatment group when controlling for the other variables in the regressions. $\gamma_{i}$ captures the average change in the violation ratio for all companies from 
before to after the treatment year. Finally, $\delta$ is the parameter of interest encapsulating the treatment effect, i.e. the change in the inverse measure of water quality when going from cost-of-service to price cap regulation.

The second model is a multi-period difference-in-differences model, where we estimate a treatment effect for each year before and after a chosen base year. ${ }^{9}$ The equation looks as follows:

$$
y_{i t}=\alpha_{t}+\tau_{i}+\beta \cdot D_{i}+\sum_{j=n, j \neq b}^{N} \delta_{j} \cdot D_{i} \cdot I[t=j]+\epsilon_{i t},
$$

where $n$ is the first year and $N$ is the last year in the data. Instead of including a constant as in Eq. (1), we include time fixed effects, $\alpha_{t}$, that measure the evolution in the inverse measure of water quality, $y_{i t}$, for the control group. The $\delta_{j}$ 's are the parameters of interest. They measure the change in the inverse measure of water quality, $y_{i t}$, for the treatment group with respect to the base year, $b$, relative to the evolution in $y_{i t}$ for the control group. Thus, in Eq. (2) we estimate annual treatment effects before and after treatment, whereas in Eq. (1) we estimate one treatment effect across all years.

We chose 2008 as the base year. This is the earliest year in the data. The law leading to the price cap in 2011 was passed in 2009. Therefore, 2008 is not likely to be affected by a potential announcement effect. In the appendix, we present estimation results where we use different base years.

The advantage of the multi-period model in Eq. (2) is that it reveals information about the yearly effect of regulation. For instance, it allows us to assess whether the effect of regulation accrues over time. The advantage of Eq. (1) is that it yields a more precise estimate of the treatment effect, subject to the assumption that the treatment effect is constant over time.

Equations (1) and (2) do not include any other explanatory variables except from the ones measuring the treatment effect(s), company-level fixed effects, and the evolution of the dependent variable (the inverse measure of water quality) for the control group. This is because the applied data do not contain additional information about the companies in the control group. However, note that in both models (1) and (2), we control for time invariant differences between companies by including fixed effects in the model. ${ }^{10}$

\footnotetext{
9 Schmieder et al. (2019), who study the effects of worker displacement, use a comparable design.

10 It does not affect the treatment estimates whether or not we include company-level fixed effects in an unweighted regression (where all companies have the same weight). This follows from (i) the fact that our difference-in-differences estimator already controls for group-level fixed effects by eliminating level differences between the treatment group and the control group; see Angrist and Pischke (2009), and (ii) the fact that we work with a balanced panel; see Lechner et al. (2016). However, in the results section we also present estimates from weighted regressions, where we weight on each company's yearly number of water samples. In these models, it makes a (small) difference whether we include company-level fixed effects in the regression or not. The intuition for this result is that when using weights that vary over time within companies, the data set in a statistical sense becomes unbalanced, and the estimation results get affected by the fixed effects. Therefore, we include company-level fixed effects in the models.
} 


\section{Data}

As a measure of (inverse) water quality we use the share of microbiological samples that contain a microbiological violation (in the rest of the paper named the violation ratio). Each company's drinking water is regularly tested to make sure that the water does not contain an amount of microbiological content that violates legally set thresholds. The water companies are in most cases able to prevent such violations, caused by leaky pipes etc.; see the Danish Nature Agency and the Danish Health Authority (2012), and the Danish Nature Agency (2013).

The water samples are tested for microbiological content, and have to meet certain legally set thresholds. The Danish rules in this area follow the EU's Drinking Water Directive. We use samples of drinking water that are required according to the Directive, as well as samples included in a municipal control program and hence approved by the Danish authorities. ${ }^{11}$ The control program decides the number of legally required tests. Correspondingly, we consider violations of the substances that are part of this program. These include coliform bacteria, e coli, bacterial count, and enterococcus. We categorize a test as violated if the level of at least one of the substances exceeds the legally set threshold. ${ }^{12}$

We use data from 2008 to 2016 from the national Danish well database, Jupiter, administered by GEUS (Geological Survey of Denmark and Greenland). The data from the Jupiter database is considered to have high quality for at least two reasons. First, the water samples are analyzed by independent laboratories, who report test results directly to the database. The water companies therefore cannot influence the generation of the test result. Secondly, the responsible municipality or GEUS validates the data before publication. However, the Jupiter database does not contain any additional (time variant) information about the companies.

The database contains plant-level information about drinking water samples and volume of extracted water with the aim of monitoring drinking water quality. There is a difference between a water company and a plant. The plants are units from where the water is passed on to the consumers. A water company is an administrative unit that might own more than one plant.

We have linked plants to companies, since the economic regulation is determined by the size of the companies, not the size of the plants. For some companies, the database provides information about company-plant linkage. However, for the companies where the database lacks this information, we have manually attached the information. ${ }^{13}$

To sum up, the Jupiter data from GEUS provides valuable information about the water quality and size of the companies. We have information about the companies' regulatory status from the Danish Competition and Consumer Authority.

\footnotetext{
11 Some companies take their own additional water samples. However, to insure better comparison we only include results from the compulsory samples.

12 This is in line with how both GEUS and the Danish Environmental Agency define a microbiological violation.

13 Generally, we have used company-plant linkage information from municipal websites for 2020, as this in most cases also indicates company-plant linkage over the years 2008 to 2016. In addition, the Jupiter database also provides some (incomplete) information about company-plant linkages.
} 


\subsection{Treatment and control group}

We define the control group in the following way: cost-of-service regulated companies with an average extraction of water in the years before the introduction of the price cap regulation (2008-2010) above $100,000 \mathrm{~m}^{3}$. We define the treatment group as price cap regulated companies that have an average extraction of water in the years before treatment (2008-2010) below 500,000 $\mathrm{m}^{3}$. Table 2 provides an overview of how we define the control and the treatment groups.

The choice of bandwidths (i.e. the minimum and maximum size of companies to include below and above the threshold) is a trade-off between the comparability of the companies (exogeneity) and sample size. We have chosen the bandwidths to make sure that they are not too far from the threshold, increasing the likelihood that companies below and above the threshold are comparable. In Sect. 5, we change the bandwidths to see if the bandwidth's size affects the results.

Finally, as Table 2 shows, we construct two more groups consisting of small and large companies, respectively. We use these groups to see how water quality varies with size of the companies.

Table 3 shows descriptive statistics for the four groups in the years prior to treatment (2008-2010). The companies in the control and treatment groups seem comparable, measured on the number of samples and the violation ratio. The average violation ratio is 0.12 for both groups. The number of yearly samples is also fairly similar. Companies in the control group take an average of 5.6 yearly water samples throughout the period, whereas companies in the treatment group take 6.9 samples. This suggests that is reasonable to compare the violation ratio of the control and the treatment groups after the introduction of the regulation. Furthermore, the average number of samples has been nearly constant over time for the treatment and control groups; see Fig. 1. This

Table 2 Definition of the four groups

\begin{tabular}{lll}
\hline Group & Description & Number of companies \\
\hline Small & $\begin{array}{l}\text { Non-regulated companies with an average extraction } \\
\text { below } 100,000 \mathrm{~m}^{3} \text { in the years 2008-2010 }\end{array}$ & 1,296 \\
Control & $\begin{array}{l}\text { Non-regulated companies with an average extraction } \\
\text { above or equal to } 100,000 \mathrm{~m}^{3} \text { in the years } \\
\text { 2008-2010 }\end{array}$ & 282 \\
Treatment & $\begin{array}{l}\text { Regulated companies with an average extraction } \\
\text { below 500,000 } \mathrm{m}^{3} \text { in the years 2008-2010 }\end{array}$ & 113 \\
Large & $\begin{array}{l}\text { Regulated companies with an average extraction } \\
\text { above or equal to 500,000 } \mathrm{m}^{3} \text { in the years } \\
\text { 2008-2010 }\end{array}$ & 86
\end{tabular}

Note: We have not included five water companies who switch between being regulated and not being regulated during the years 2011-2016. Non-regulated refers to the cost-of-service regulated companies. The volume of extracted water can deviate from the volume of sold water due to the company's own use of water and leakages, etc

Source: Own calculations based on data from GEUS and the Danish Competition and Consumer Authority 
Table 3 Descriptive statistics for the four groups, average 2008 to 2010

\begin{tabular}{|c|c|c|c|c|c|c|}
\hline Variable & Group & Average & $\begin{array}{l}\text { Standard } \\
\text { deviation }\end{array}$ & Median & Minimum & Maximum \\
\hline \multicolumn{7}{|c|}{$\begin{array}{l}\text { Water extraction, } 1000 \\
\mathrm{~m}^{3}\end{array}$} \\
\hline & Small & 35 & 25 & 29 & 0.5 & 99 \\
\hline & Control & 147 & 40 & 139 & 100 & 326 \\
\hline & Treatment & 307 & 92 & 295 & 26 & 489 \\
\hline & Large & 3,095 & 6,908 & 1,442 & 535 & 61,544 \\
\hline \multicolumn{7}{|c|}{ Samples, no } \\
\hline & Small & 3.1 & 1.8 & 2.0 & 1.0 & 15.7 \\
\hline & Control & 5.6 & 2.6 & 5.7 & 1.7 & 23.7 \\
\hline & Treatment & 6.9 & 4.1 & 6.0 & 1.7 & 23.0 \\
\hline & Large & 41.5 & 67.3 & 22.2 & 2.3 & 438.7 \\
\hline \multicolumn{7}{|c|}{ Violation ratio } \\
\hline & Small & 0.17 & 0.19 & 0.14 & 0 & 1 \\
\hline & Control & 0.12 & 0.12 & 0.11 & 0 & 0.67 \\
\hline & Treatment & 0.12 & 0.13 & 0.08 & 0 & 0.67 \\
\hline & Large & 0.08 & 0.07 & 0.07 & 0 & 0.38 \\
\hline
\end{tabular}

Note: The numbers reflect (unweighted) company-averages across the years 2008 to 2010. This explains why some maximum and minimum values are decimal numbers

Source: GEUS and the Danish Competition and Consumer Authority

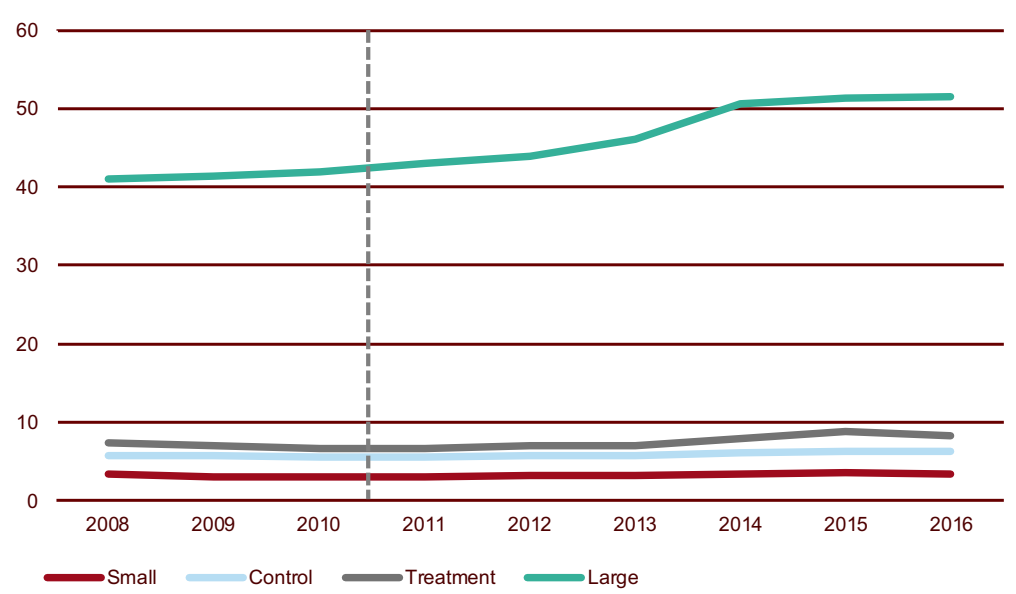

Note: The vertical line shows the introduction of the regulation between 2010 and 2011 .

Source: Own calculations based on data from GEUS and the Danish Competition and Consumer Authority.

Fig. 1 Average number of samples, 2008-2016 


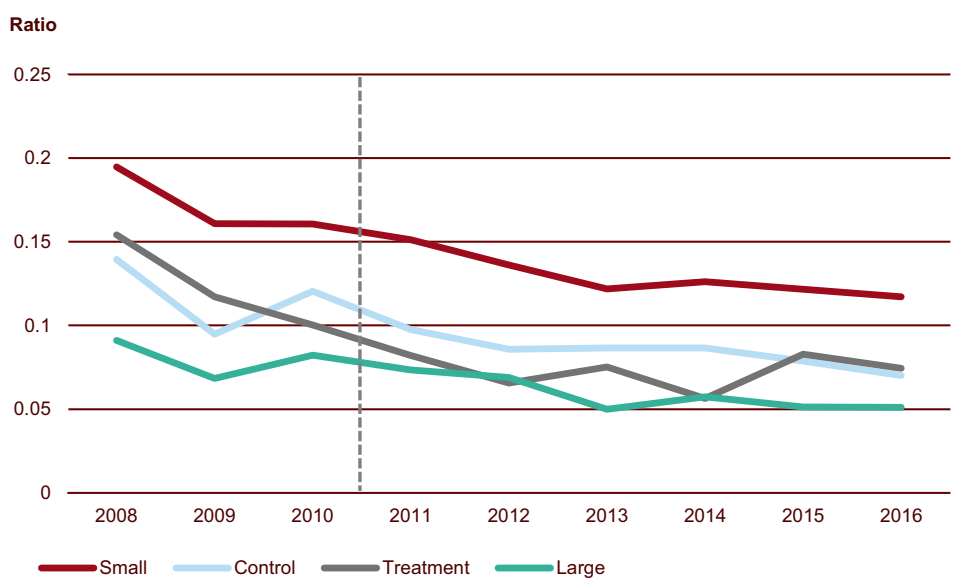

Note: The vertical line shows the introduction of the regulation between 2010 and 2011 . The numbers are weighted averages. Source: Own calculations based on data from GEUS and the Danish Competition and Consumer Authority.

Fig. 2 Violation ratio, 2008 to 2016

indicates that a potential treatment effect does not reflect changes in sample-taking behavior between the control and the treatment groups.

Moreover, one can note from Table 3 that the violation ratio is lower for the large companies than for the small ones.

\section{Results}

In this section, we present the results from the analysis and perform sensitivity analyses. The first crucial thing to note is that the violation ratio evolves almost identically for the control and the treatment group over time; see Fig. 2. Hence, it does not look like the violation ratio increased for the treatment group after the implementation of the price caps from 2011 relative to the violation ratio for the control group. ${ }^{14}$ This indicates that the introduction of the price cap in 2011 has not led to water quality deterioration compared to companies regulated with the cost-of-service regulation.

The second thing to note is that the violation ratio decreases over time for all company sizes, which reflects a general improvement in water quality over the period. A final thing to note is that the violation ratio is larger for small water companies than for the large ones throughout the whole period.

We estimate the econometric models presented in Sect. 3 using data for companies belonging to the treatment and control groups to obtain parametric estimates as well

\footnotetext{
14 By comparing trends for the control group and treatment group in the years before treatment (2008-2010), one can perform a validity check of the identifying assumption, i.e. that the split into a treatment and a control group, caused by the legislative change, was random for companies around the $200,000 \mathrm{~m}^{3}$ level. As shown in Fig. 2, the lines somehow follow the same decreasing trend over the three years, even though the control group trajectory takes a slight jump in 2010.
} 
Table 4 Regression results from the basic difference-indifferences model

\begin{tabular}{|c|c|c|}
\hline & \multicolumn{2}{|c|}{$\begin{array}{l}\text { Dependent variable: } \\
\text { Violation ratio }\end{array}$} \\
\hline & $\begin{array}{l}\text { Unweighted } \\
\text { (OLS) }\end{array}$ & $\begin{array}{l}\text { Weighted } \\
\text { (WLS) }\end{array}$ \\
\hline \multirow[t]{2}{*}{ Intercept } & $0.283 * * *$ & $0.255^{* * * *}$ \\
\hline & $(0.005)$ & $(0.005)$ \\
\hline \multirow[t]{2}{*}{ Treatment group dummy } & $-0.122 * * *$ & $-0.095 * * *$ \\
\hline & $(0.009)$ & $(0.008)$ \\
\hline \multirow[t]{2}{*}{ Time effect 2011-2016 } & $-0.034 * * *$ & $-0.037 * * *$ \\
\hline & $(0.007)$ & $(0.006)$ \\
\hline \multirow[t]{2}{*}{ Treatment effect 2011-2016 } & $-\mathbf{0 . 0 1 7}$ & $-0.026 * *$ \\
\hline & $(0.013)$ & $(0.012)$ \\
\hline Company-level fixed effects & YES & YES \\
\hline Observations & 3,555 & 3,555 \\
\hline $\mathrm{R}^{2}$ & 0.264 & 0.281 \\
\hline Adjusted $\mathrm{R}^{2}$ & 0.172 & 0.191 \\
\hline Residual Std. Error $(\mathrm{df}=3551)$ & 0.142 & 0.317 \\
\hline F Statistic $(\mathrm{df}=3 ; 3551)$ & $2.860 * * *$ & $3.124 * * *$ \\
\hline
\end{tabular}

Bold is used to highlight the estimated parameter for the treatment effect

Standard errors (in parentheses) are clustered on company-level. * $p<$ $0.1 ; * *<<0.05 ; * * * p<0.01$

as measures of uncertainty. In Table 4, we show the results from an estimation of Eq. (1) in an unweighted and a weighted regression, respectively. In the unweighted regression, all companies in the data get the same weight, irrespective of the number of water samples they carry out. In the weighted model, we weight based on the number of samples of each company each year. This means that companies within the control and treatment groups that take more samples get a higher weighting when we estimate the effect of the regulation on water quality. Hence, the two approaches differ in the way they weight companies and samples. In the unweighted estimation, all companies get the same weight. This means that a water sample taken by a company that takes few yearly samples gets a higher weight than a sample taken by a company that takes many yearly samples. Oppositely, in the weighted estimation, a company gets a higher weight the more samples it takes, but all samples get equal weights. Therefore, which approach to use depends on whether companies or samples should weight equally in the estimation. Since the answer to this question is not clear-cut, all estimations are carried out using both approaches.

As Table 4 shows, we estimate a negative treatment effect in both the unweighted and the weighted difference-in-differences model. A negative treatment effect means that the violation ratio on average decreased (water quality increased) for the companies in the treatment group relative to the violation ratio for those in the control group 

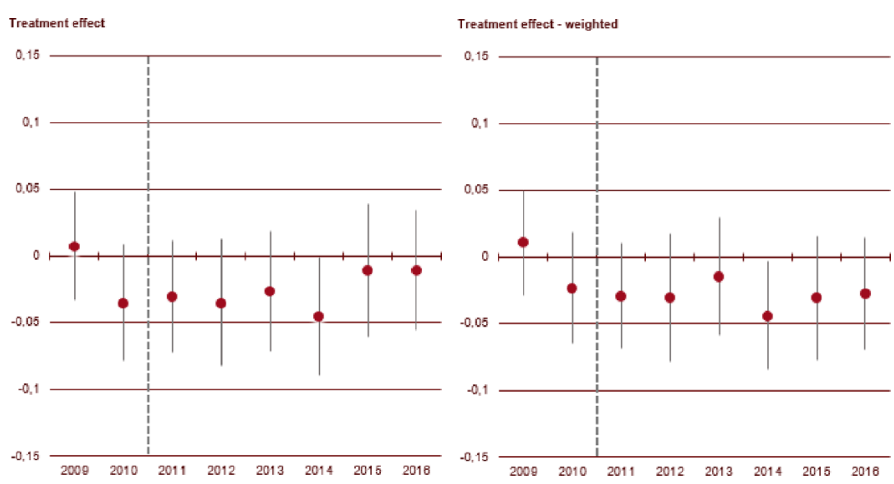

Note: Each point in the graph shows the estimated (treatment) effect on the violation ratio of the change in regulation $\left(\delta_{j}\right)$ for the relevant year from equation (2). The grey solid lines are 95-percent confidence bands. Standard errors are clustered at company level. The dotted line indicates time of treatment.

Fig. 3 Annual treatment effects from multi-period difference-in-differences model

after the introduction of the price cap regulation in 2011. The parameter estimate in the weighted model is -0.026 and statistically significant on a 5 percent level. The estimate in the unweighted model is -0.017 , i.e. numerically only slightly lower than the estimate from the weighted model. However, the estimate from the unweighted model is not significant on a 5 percent level.

Estimating the multi-period difference-in-differences model in Eq. (2) yields similar results; see Fig. 3. The figure shows the estimated treatment effects for the period 2008-2016 in the unweighted and the weighted model. In all years (after the introduction of the price caps), the treatment effect is negative, indicating that the treatment group of regulated companies experienced a sharper decrease in the violation ratio (increase in water quality) after the change in regulation than the control group. Yet, for all but one of the post-treatment years (2011-2016), the estimates are not statistically significant on a 5-percent level.

\subsection{Sensitivity tests}

In the following, we perform a sensitivity test of Eq. (2), the multi-period difference-indifferences model. We test the sensitivity in two ways by (i) adjusting the bandwidths that divide the water companies into a control and a treatment group, and (ii) by changing the base year in the equation.

If adjusting the bandwidths does not change the results significantly, it indicates that the results are robust; see Imbens and Lemieux (2008). Widening the bandwidths will increase sample size and lower standard errors, while potentially decreasing the likelihood that we can compare the control and treatment group. Narrowing the bands will increase standard errors, but also increase the likelihood that the companies are comparable. 
Table 5 Sensitivity test-bandwidths

\begin{tabular}{llllll}
\hline & \multicolumn{2}{l}{ Limit, $\mathrm{m}^{3}$} & & \multicolumn{2}{l}{ Number of companies } \\
\cline { 5 - 6 } \cline { 5 - 6 } & Lower & Upper & & Control group & Treatment group \\
\hline Wider bands & 50,000 & $1,000,000$ & & 627 & 142 \\
Baseline bands & 100,000 & 500,000 & & 282 & 113 \\
Narrower bands & 150,000 & 300,000 & & 107 & 60 \\
\hline
\end{tabular}
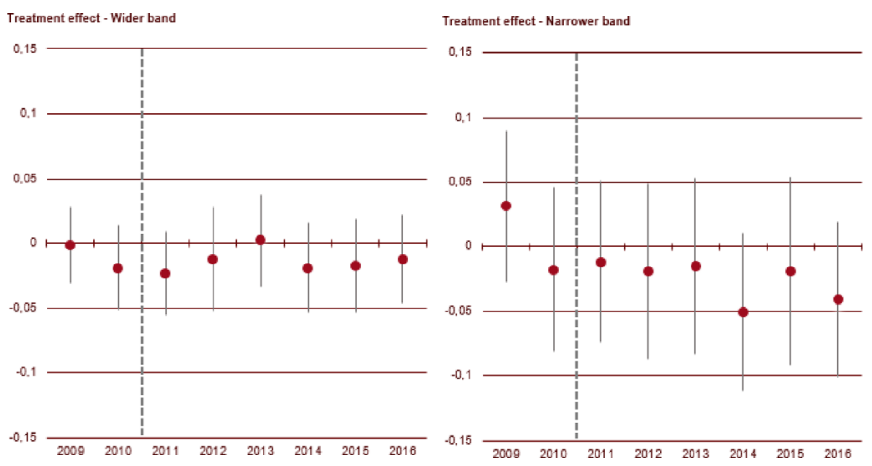

Note: Each dot in the graph shows the estimated (treatment) effect on the violation ratio of the change in regulation $\left(\delta_{j}\right)$ for the relevant year from equation (2) using the WLS estimation. The grey solid lines are 95 -percent confidence bands. Standard errors are clustered on company level. The dotted line indicates the time of treatment.

Fig. 4 Results from multi-period difference-in-differences model using different bandwidths

Table 5 shows the different bandwidths that we use to carry out the sensitivity test. We estimate the econometric model when using both narrower and wider bandwidths.

In Fig. 4, we present the treatment effects of estimating Eq. (2) using the different bandwidths presented in Table 5. The main things to derive from the graphs are that (i) adjusting the bandwidths overall does not alter the treatment effects, and (ii) narrowing the bandwidths increases standard errors, whereas widening them lowers standard errors as expected. The fact that the treatment effects do not change when the size of the bandwidths change suggests that the estimated treatment effects are robust; see Imbens and Lemieux (2008). ${ }^{15}$

Finally, we have estimated Eq. (2) using different base years. We run the model with three alternative base years or periods: 2009, 2010 and 2008-2010. Essentially, using another base year means that we leave out the $\delta_{j}$ estimate for this year when

\footnotetext{
15 Figure 4 shows treatment effects based on weighted estimations, where the number of water samples of each company is used as weights. The unweighted estimation yields results similar to Fig. 4.
} 
estimating the parameter in Eq. (2). The overall conclusion from these tests is that the results are robust in relation to changing the base year. ${ }^{16}$ See the appendix for results.

\section{Other measures of security of supply}

In the empirical analysis, we found that price caps did not seem to cause deterioration in drinking water quality. The analysis actually suggested that the price cap regulation might have improved drinking water quality compared to Danish drinking water companies not regulated with price caps.

The focus was on drinking water quality, because high quality data are available for drinking water companies regulated with and without price caps for a long timeperiod, also covering years before the introduction of the price caps. In this section, we briefly look at other indicators of quality and security of supply in order to see if they change in step with water quality.

Two descriptive analyses appear to support the conclusion that the price cap regulation of Danish drinking water companies has not reduced security of supply. However, note that data for the other indicators of security of supply are only available for larger companies that are all regulated with price caps. It is therefore difficult to draw strong conclusions on the effect of the price cap from these data.

The first descriptive analysis inspects the overall change in water leakage for a number of large drinking water companies. Leakage of water can be considered an indicator of the quality and overall maintenance level of the infrastructure used to provide water to costumers. Overall water leakage for large water companies has been reduced since the introduction of the price cap regulation in 2011, see Fig. 5. There was an increase in water leakage in 2018, but according to DANVA (Danish Water and Wastewater Association) this was caused by unusual weather conditions in $2018 .{ }^{17}$ Overall, it appears that the introduction of the price caps have not led to an increase in water leakage.

In the second descriptive analysis, we investigate whether cost efficient (large) Danish drinking water companies have lower security of supply compared to cost inefficient companies. If that is the case, it may reflect that drinking water companies with low costs have obtained the low costs at the expense of a high security of supply.

Our measure of cost efficiency is the efficiency scores obtained from a stochastic frontier benchmarking carried out for all large Danish drinking water companies. As described in Sect. 2, this benchmarking model provides input to the yardstick regulation of the largest companies. ${ }^{18}$ A high efficiency score means that the company

\footnotetext{
16 Using 2010, the year just before the regulatory change, as the base year, the model yields positive parameter estimates for some years in the unweighted model. However, none of these are significantly positive.

17 Summer 2018 was very dry, which according to DANVA (Danish Water and Wastewater Association) led to burst water pipelines and increased water leakage in that year.

18 As described in Sect. 2, benchmarking models are applied in the regulation. The applied benchmarking models focus on cost and production of the companies, i.e. do not include measures of the security of supply of the companies. The applied benchmarking models are described in the Danish Competition and Consumer Authority (2020).
} 


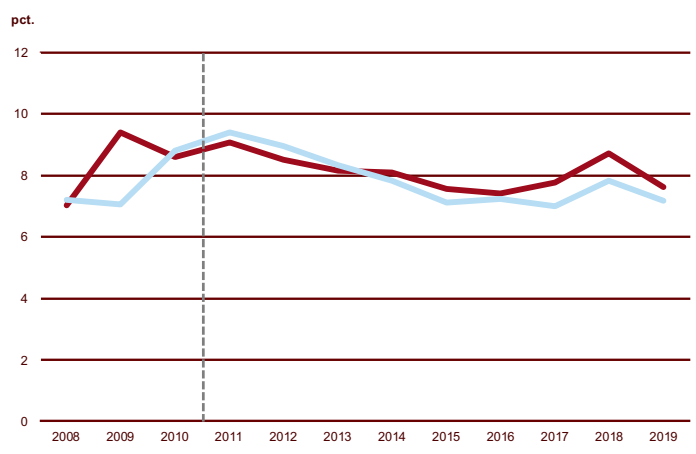

Unbalanced panel Balanced panel

Note: The vertical line shows the introduction of the price cap regulation between 2010 and 2011 . The red line shows average water leakage for an unbalanced panel of 79 large Danish drinking water companies, while the blue line shows the water leakage of a balanced panel of 29 drinking water companies where data are available for every year. All companies are large and were regulated with price caps from 2011.

Source: DANVA (Danish Water and Wastewater Association).

Fig. 5 Water leakage in large Danish drinking water companies

operates with low costs, while a low efficiency score means that the company has high costs compared to other drinking water companies.

Our measure of security of supply is an index calculated as the simple mean of four (standardized) indicators of security of supply. ${ }^{19}$ (1) Duration of interruptions in water supply (average minutes with interruption in water supply per customer), (2) Water leakage in percent, (3) Average number of water pipe bursts per $10 \mathrm{~km}$ of water pipe and (4) Inverse water quality. ${ }^{20}$

A high value of the index means that security of supply is low, while a low value means that security of supply is high (e.g. no interruptions in supply and low water leakage). There appears to be a negative correlation between cost efficiency and the index for low security of supply, see Fig. $6{ }^{21}$ This implies that cost efficient drinking water companies tend to have a relatively high level of security supply, while inefficient companies also appear to have poor performance with respect to providing security of supply. This result is consistent with the finding that drinking water companies with price caps - who presumably have lower costs - seem to have a larger improvement in water quality than companies in the control group that are subject to cost-of-service regulation.

19 Data for these indicators of security of supply have been published by the Danish Environmental Protection Agency since 2017 for all larger drinking water companies (same size as companies that became regulated with price caps in 2011). In this time period, the benchmarking models have generally only been used to calculate efficiency scores for drinking water companies selling more than $800,000 \mathrm{~m}^{3}$ water annually.

20 The (inverse) measure of water quality (and other indicators) is based on information from the Danish Environmental Protection Agency. Their measure of water quality is not identical to our definition of the violation ratio.

21 The negative slope is statistically significant at a 1 per cent level. 


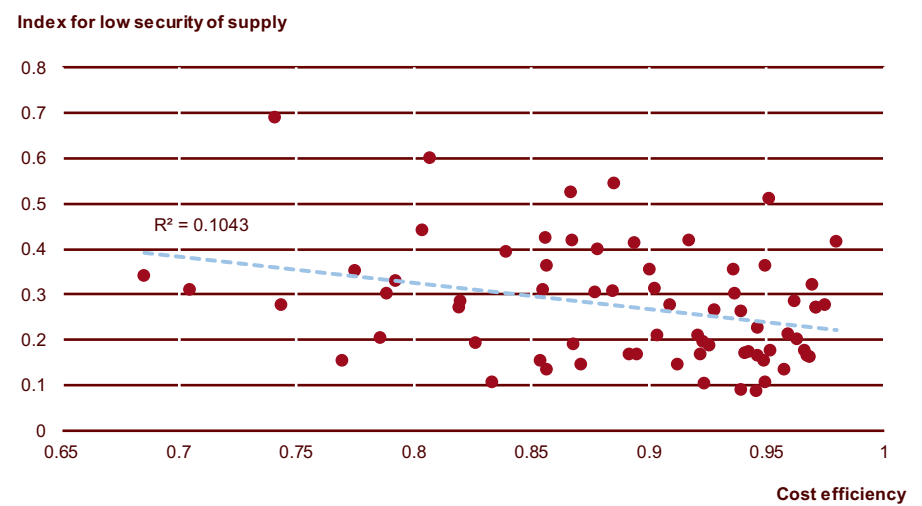

Note: The index for security of supply is an average of normalized data of four different indicators of security of supply (interruptions in water supply, water leakage, pipe bursts and water quality). For an index value equal to 1, the company has the lowest performance of security of supply across all indicators. The blue line show the linear correlation. The data are for 2018-2019. Source: Data from the Danish Environmental Protection Agency and the Danish Competition and Consumer Authority.

Fig. 6 Cost efficiency and (low) security of supply for large drinking water companies

\section{Conclusion and discussion}

This study has examined the effect of price cap regulation of Danish drinking water companies on water quality for a balanced panel of drinking water companies for the period 2008 to 2016. The price cap was introduced in 2011 for water companies above a certain threshold size.

This introduction of the price cap makes it possible to estimate the effect of the price cap on water quality using quasi-experimental variation. More specifically, we use a difference-in-differences approach comparing the change in water quality before/after implementation of price caps in 2011 for a treatment group of 113 companies with a size fairly close to the threshold for being regulated, and a control group of 282 companies below, but still fairly close to the threshold size for being regulated.

Based on different statistical models (a simple difference-in-differences model and a multi-period difference-in-differences model), we find that the price cap has not caused a deterioration in water quality. It actually seems more likely that the price cap regulation has improved the quality of the drinking water.

Sensitivity analyses suggest that the results are robust to changes in the bandwidths that define the size of the control and the treatment groups, and to the base year applied in the multi-period difference-in-difference model. Descriptive analyses based on other indicators of the quality of the drinking water companies also appear to support the overall conclusion.

A number of previous studies have observed that a shift from cost-of-service or rateof-return regulation to price cap regulation have led to a deterioration in the quality or security of supply of a good provided by a monopoly. For example, empirical studies for the electricity sector generally find that price cap regulation lowers security of supply.

The regulatory framework in Denmark and the ownership structure of Danish drinking water companies may potentially explain why price cap regulation has not reduced 
water quality in Denmark. Danish drinking water companies are owned by local governments (municipalities) or by customers and are not allowed to pay out profits to their owners. Thus, in practice the Danish price cap regulation put cost reduction requirements on the Danish drinking water companies, but the price caps do not provide the same high-powered incentive to additional cost reductions as for profit maximizing companies that are allowed to pay out profits to their owners. In addition, it has been put forward that there is a strong commitment in the Danish drinking water companies to delivering high water quality because the companies are customer owned or owned by local governments. In this case, it might be that the companies regulated with price caps (cost reduction requirements) prioritize reducing unnecessary costs (reducing $\mathrm{X}$-inefficiency) and maintaining water quality, instead of reducing water quality and maintaining X-inefficiency.

As noted, some of our results indicated that the price cap regulation might have improved drinking water quality. It is not obvious what may have led to such an effect. However, recent research has measured the quality of management practices in different countries and different sectors and found that differences in management practices have a large impact on productivity for different companies, see Bloom et al. (2014). It appears from this research that the quality of management practices is better in sectors exposed to competition than in sectors not exposed to competition. As there is no natural competition in the drinking water sector, this finding suggests that the quality of management practices should be low in this sector. However, the price cap regulation combined with RPI-X and yardstick regulation seeks to imitate the competitive pressure in competitive sectors. Potentially, the introduction of price cap regulation may have led to a general improvement in management practices of the regulated firms, which could also have caused an improvement in management practices with respect to quality in the regulated companies.

Open Access This article is licensed under a Creative Commons Attribution 4.0 International License, which permits use, sharing, adaptation, distribution and reproduction in any medium or format, as long as you give appropriate credit to the original author(s) and the source, provide a link to the Creative Commons licence, and indicate if changes were made. The images or other third party material in this article are included in the article's Creative Commons licence, unless indicated otherwise in a credit line to the material. If material is not included in the article's Creative Commons licence and your intended use is not permitted by statutory regulation or exceeds the permitted use, you will need to obtain permission directly from the copyright holder. To view a copy of this licence, visit http://creativecommons.org/licenses/by/4.0/.

\section{Appendix}

The table shows the results from an estimation of the multi-period difference-indifferences model, Eq. (2), using different years as base years. The first regression (base year 2008) corresponds to estimation results shown in Fig. 3 in the main text. Results in the table are based on weighted regression, where the number of samples for each companies is used as weights (overall, the corresponding unweighted regressions yield similar results). 


\begin{tabular}{|c|c|c|c|c|}
\hline & \multicolumn{4}{|c|}{ Dependent variable: Violation ratio } \\
\hline & Base year 2008 & Base year 2009 & Base year 2010 & $\begin{array}{l}\text { Base year } \\
2008-2010\end{array}$ \\
\hline $\begin{array}{l}\text { Treatment group } \\
\text { dummy }\end{array}$ & $\begin{array}{l}-0.091 * * * \\
(0.016)\end{array}$ & $\begin{array}{l}-0.080 * * * \\
(0.014)\end{array}$ & $\begin{array}{l}-0.114^{* * *} \\
(0.012)\end{array}$ & $\begin{array}{l}-0.094 * * * \\
(0.008)\end{array}$ \\
\hline $\begin{array}{l}\text { Time effect } \\
2008-2010\end{array}$ & & & & $\begin{array}{l}0.255^{* * *} \\
(0.005)\end{array}$ \\
\hline Time effect 2008 & $\begin{array}{l}0.278 * * * \\
(0.010)\end{array}$ & $\begin{array}{l}0.278^{* * *} \\
(0.010)\end{array}$ & $\begin{array}{l}0.278 * * * \\
(0.010)\end{array}$ & \\
\hline Time effect 2009 & $\begin{array}{l}0.231^{* * *} \\
(0.008)\end{array}$ & $\begin{array}{l}0.231 * * * \\
(0.008)\end{array}$ & $\begin{array}{l}0.231 * * * \\
(0.008)\end{array}$ & \\
\hline Time effect 2010 & $\begin{array}{l}0.256 * * * \\
(0.008)\end{array}$ & $\begin{array}{l}0.256^{* * * *} \\
(0.008)\end{array}$ & $\begin{array}{l}0.256^{* * * *} \\
(0.008)\end{array}$ & \\
\hline Time effect 2011 & $\begin{array}{l}0.237 * * * \\
(0.008)\end{array}$ & $\begin{array}{l}0.237 * * * \\
(0.008)\end{array}$ & $\begin{array}{l}0.237 * * * \\
(0.008)\end{array}$ & $\begin{array}{l}0.238 * * * \\
(0.008)\end{array}$ \\
\hline Time effect 2012 & $\begin{array}{l}0.217 * * * \\
(0.008)\end{array}$ & $\begin{array}{l}0.217 * * * \\
(0.008)\end{array}$ & $\begin{array}{l}0.217 * * * \\
(0.008)\end{array}$ & $\begin{array}{l}0.217 * * * \\
(0.008)\end{array}$ \\
\hline Time effect 2013 & $\begin{array}{l}0.214 * * * \\
(0.007)\end{array}$ & $\begin{array}{l}0.214 * * * \\
(0.007)\end{array}$ & $\begin{array}{l}0.214 * * * \\
(0.007)\end{array}$ & $\begin{array}{l}0.214 * * * \\
(0.007)\end{array}$ \\
\hline Time effect 2014 & $\begin{array}{l}0.220 * * * \\
(0.007)\end{array}$ & $\begin{array}{l}0.220 * * * \\
(0.007)\end{array}$ & $\begin{array}{l}0.220 * * * \\
(0.007)\end{array}$ & $\begin{array}{l}0.220 * * * \\
(0.007)\end{array}$ \\
\hline Time effect 2015 & $\begin{array}{l}0.213 * * * \\
(0.007)\end{array}$ & $\begin{array}{l}0.213 * * * \\
(0.007)\end{array}$ & $\begin{array}{l}0.213 * * * \\
(0.007)\end{array}$ & $\begin{array}{l}0.213 * * * \\
(0.007)\end{array}$ \\
\hline Time effect 2016 & $\begin{array}{l}0.207 * * * \\
(0.007)\end{array}$ & $\begin{array}{l}0.207 * * * \\
(0.007)\end{array}$ & $\begin{array}{l}0.207 * * * \\
(0.007)\end{array}$ & $\begin{array}{l}0.207 * * * \\
(0.007)\end{array}$ \\
\hline Treatment effect 2008 & & $\begin{array}{l}-\mathbf{0 . 0 1 1} \\
(0.020)\end{array}$ & $\begin{array}{l}\mathbf{0 . 0 2 3} \\
(0.021)\end{array}$ & \\
\hline Treatment effect 2009 & $\begin{array}{l}\mathbf{0 . 0 1 1} \\
(0.020)\end{array}$ & & $\begin{array}{l}\mathbf{0 . 0 3 4} * \\
(0.020)\end{array}$ & \\
\hline Treatment effect 2010 & $\begin{array}{l}-\mathbf{0 . 0 2 3} \\
(0.021)\end{array}$ & $\begin{array}{l}-\mathbf{0 . 0 3 4} * \\
(0.020)\end{array}$ & & \\
\hline Treatment effect 2011 & $\begin{array}{l}-\mathbf{0 . 0 2 9} \\
(0.020)\end{array}$ & $\begin{array}{l}-\mathbf{0 . 0 4 0} * * \\
(0.019)\end{array}$ & $\begin{array}{l}-\mathbf{0 . 0 0 6} \\
(0.018)\end{array}$ & $\begin{array}{l}-\mathbf{0 . 0 2 6} * \\
(0.015)\end{array}$ \\
\hline Treatment effect 2012 & $\begin{array}{l}-\mathbf{0 . 0 3 0} \\
(0.025)\end{array}$ & $\begin{array}{l}-\mathbf{0 . 0 4 1} * \\
(0.023)\end{array}$ & $\begin{array}{l}-\mathbf{0 . 0 0 7} \\
(0.020)\end{array}$ & $\begin{array}{l}-\mathbf{0 . 0 2 7} \\
(0.019)\end{array}$ \\
\hline Treatment effect 2013 & $\begin{array}{l}-\mathbf{0 . 0 1 4} \\
(0.022)\end{array}$ & $\begin{array}{l}-\mathbf{0 . 0 2 5} \\
(0.019)\end{array}$ & $\begin{array}{l}\mathbf{0 . 0 0 9} \\
(0.020)\end{array}$ & $\begin{array}{l}-\mathbf{0 . 0 1 1} \\
(0.017)\end{array}$ \\
\hline Treatment effect 2014 & $\begin{array}{l}-\mathbf{0 . 0 4 4} * * \\
(0.021)\end{array}$ & $\begin{array}{l}-\mathbf{0 . 0 5 5} * * * \\
(0.019)\end{array}$ & $\begin{array}{l}-\mathbf{0 . 0 2 1} \\
(0.018)\end{array}$ & $\begin{array}{l}-\mathbf{0 . 0 4 0} * * * \\
(0.015)\end{array}$ \\
\hline Treatment effect 2015 & $\begin{array}{l}-\mathbf{0 . 0 3 1} \\
(0.024)\end{array}$ & $\begin{array}{l}-\mathbf{0 . 0 4 2} * \\
(0.022)\end{array}$ & $\begin{array}{l}-\mathbf{0 . 0 0 7} \\
(0.020)\end{array}$ & $\begin{array}{l}-\mathbf{0 . 0 2 7} \\
(0.019)\end{array}$ \\
\hline
\end{tabular}


Dependent variable: Violation ratio

\begin{tabular}{|c|c|c|c|}
\hline Base year 2008 & Base year 2009 & Base year 2010 & $\begin{array}{l}\text { Base year } \\
2008-2010\end{array}$ \\
\hline
\end{tabular}

\begin{tabular}{lllll}
\hline Treatment effect 2016 & $\mathbf{- 0 . 0 2 7}$ & $\mathbf{- 0 . 0 3 8 *}$ & $\mathbf{- 0 . 0 0 4}$ & $\mathbf{- 0 . 0 2 4}$ \\
& $(0.022)$ & $(0.020)$ & $(0.017)$ & $(0.016)$ \\
Observations & 3,555 & 3,555 & 3,555 & 3,555 \\
$R^{2}$ & 0.516 & 0.516 & 0.516 & 0.512 \\
Adjusted $R^{2}$ & 0.453 & 0.453 & 0.453 & 0.449 \\
Residual Std. Error & $0.316(d f=3144)$ & $0.316(d f=$ & $0.316(d f=$ & $0.317(d f=$ \\
& & $3144)$ & $3144)$ & $3148)$ \\
F Statistic & $8.171 * * *$ & $8.171 * * *$ & $8.171 * * *$ & $8.123 * * *$ \\
& $(d f=411 ; 3144)$ & $(d f=411 ;$ & $(d f=411 ;$ & $(d f=407 ;$ \\
& & $3144)$ & $3144)$ & $3148)$
\end{tabular}

Bold is used to highlight the estimated parameter for the treatment effect

Fixed effects are included in the estimation. Standard errors (in parentheses) are clustered on company-level. $* p<0.1 ; * *<<0.05 ; * * * p<0.01$

\section{References}

Ai, C., Martinez, S., \& Sappington, D. E. M. (2004). Incentive regulation and telecommunications service quality. Journal of Regulatory Economics, 26, 263-285.

Ai, C., \& Sappington, D. E. M. (2005). Reviewing the impact of incentive regulation on U.S. telephone service quality. Utilities Policy, 13, 2001-2210.

Angrist, J. D., \& Krueger, A. B. (2001). Instrumental variables and the search for identification: From supply and demand to natural experiments. Journal of Economic Perspectives., 15(4), 69-85.

Angrist, J. D., \& Pischke, J. S. (2009). Mostly Harmless Econometrics. Princeton University Press.

Banerjee, A. (2003). Does incentive regulation "cause" degradation of retail telephone service quality? Information Economics and Policy, 15, 243-269.

Black, S. E. (1999). Do better schools matter? parental valuation of elementary education. The Quarterly Journal of Economics, 114(2), 577-599.

Bloom, N., Lemos, R., Sadun, R., Scur, D., \& Van Reenen, J. (2014): The New Empirical Economics of Management. NBER Working Paper 20102. National Bureau of Economic Research.

Bound, J., Jaeger, D. A., \& Baker, R. M. (1995). Problems with instrumental variables estimation when the correlation between the instruments and the endogenous explanatory variable is weak. Journal of the American Statistical Association, 90(430), 443-450.

Clements, M. (2004). Local telephone quality of service: A framework and empirical evidence. Telecommunications Policy, 28, 413-426.

Cook, T. D. (2008). Waiting for life to arrive: A history of the regression-discontinuity design in psychology, statistics and economics. Journal of Econometrics, 142, 636-654.

Hilton Boon, M., Craig, P., Thomson, H., Campbell, M., \& Moore, L. (2021). Regression discontinuity designs in health a systematic review. Epidemiology, 32(1), 87-93.

Imbens, G., \& Lemieux, T. (2008). Regressions discontinuity designs: A guide to practice. Journal of Econometrics, 142(2), 615-635.

Joskow, P.J. (2007): Regulation of Natural Monopoly. Chapter 16 in Polinsky, A.M. and S. Shavell (eds.) Handbook of Law and Economics, vol. 2. Elsevier B.V., Amsterdam

Lechner, M., Rodriguez-Planas, N., \& Kranz, D. F. (2016). Difference-in-difference estimation by FE and OLS when there is panel non-response. Journal of Applied Statistics, 43, 2044-2052.

Lee, D. S., \& Lemieux, T. (2010). Regression discontinuity designs in economics. Journal of Economic Literature, 48(2), 281-355. 
Li, H., Li, J., Lu, Y., \& Xie, H. (2020). Housing wealth and labor supply: Evidence from a regressions discontinuity design. Journal of Public Economics, 183, 104139.

Reichl, J., Kollmannn, A., Tichler, R., \& Schneider, F. (2008). The importance of incorporating reliability of supply criteria in a regulatory system of electricity distribution: An empirical analysis for Austria. Energy Policy, 36, 3862-3871.

Roycroft, T., \& Garcia-Murillo, M. (2000). Trouble reports as an indicator of service quality: The influence of competition, technology, and regulation. Telecommunications Policy, 24, 947-967.

Sappington, D. E. M., \& Weisman, D. L. (2010). Price cap regulation: What have we learned from 25 years of experience in the telecommunications industry? Journal of Regulatory Economics, 38, 227-257.

Sappington, D. E. M. (2005). Regulating service quality: A survey. Journal of Regulatory Economics, 27(2), $123-154$.

Schmieder, J. F., von Wachter, T. \& Heining, J. (2019). The costs of job displacement over the business cycle and its sources: Evidence from Germany, Working paper. October 2019.

Schmidthaler, M., Cohen, J., Reichl, J., \& Schmidinger, S. (2015). The effects of network regulation on electricity supply security: A European analysis. Journal of Regulatory Economics, 48, 285-316.

Ter-Martirosyan, A., \& Kwoka, J. (2010). Incentive regulation, service quality, and standards in U.S. electricity distribution. Journal of Regulatory Economics, 38, 258-273.

The Danish Competition Authority (2003): Konkurrenceredegørelse ["Competition Review"]. Report. Chapter 4. May 2003.

The Danish Competition and Consumer Authority (2020): Dokumentationsnotat til beskrivelse af Forsyningssekretariatets SFA-model [Documentation memo for the description of the Danish Water Regulatory Authority's SFA model]. Memo September 2020

The Danish Economic Councils (2004): Danish Economy. Report. Chapter 3. Autumn 2004.

The Danish Nature Agency (2013): Håndtering af overskridelser af de mikrobiologiske drikkevandsparametre ["Handling Violations of the Microbiological Drinking Water Parameters"]. Report, March 2013.

The Danish Nature Agency and the Danish Health Authority (2012): Mikrobiologiske drikkevandsforureninger 2011 ["Microbiological Violations in Drinking Water 2011 "]. Report, December 2012.

Thistlethwaite, D. L., \& Campbell, D. T. (1960). Regression-discontinuity analysis: An alternative to the ex post facto experiment. Journal of Educational Psychology, 50(6), 309-317.

Wooldridge, J. (2015). Introductory econometrics - a modern approach (6th ed.). Boston: Cengage Learning.

Publisher's Note Springer Nature remains neutral with regard to jurisdictional claims in published maps and institutional affiliations. 